Revista de Economia Política, vol. 42, n 1, pp. 207-221, janeiro-março/2022

\title{
A ação e o pensamento de Fernão Bracher, um conservador com espírito público
}

\author{
The action and thought of Fernão Bracher, \\ a conservative with public spirit
}

JOÃO VILLAVERDE*,**

JOSÉ MARCIO REGO ${ }^{x}, x \times$

\begin{abstract}
RESUMO: Este artigo reflete a trajetória de Fernão Bracher à luz dos avanços institucionais na administração pública brasileira a partir da redemocratização de 1985 . Descendente de família tradicional em São Paulo, Bracher vai canalizar seu espírito público e seu nacionalismo econômico em três oportunidades, notadamente a partir da superação do regime militar, quando preside o Banco Central do Brasil e depois se torna, a convite do amigo e ministro Luiz Carlos Bresser-Pereira, o negociador brasileiro da dívida externa. Menos teórico que Bresser, mas tão pragmático quanto ele, Bracher compartilhava a imensa curiosidade intelectual do amigo, tendo auxiliado na troca de reflexões entre os diferentes economistas envolvidos com a teoria da inflação inercial. Homem de ação, no setor privado e no setor público, Bracher tem trajetória que ilumina a superação de dificuldades presentes na política econômica nacional.
\end{abstract}

PALAVRAS-CHAVE: Economia brasileira; administração pública; dívida externa; países em desenvolvimento; Estado.

ABSTRACT: This paper reflects on the trajectory of Fernão Bracher in the light of institutional advances in the Brazilian public administration since the re-democratization of 1985 onward. Descendant of a traditional family in São Paulo, Bracher will channel his public spirit and his economic nationalism in three opportunities, notably during the postmilitary regime period, when he governed the Central Bank of Brazil and later became, at

\footnotetext{
* Mestre e doutorando em Administração Pública e Governo na Escola de Administração do Estado de São Paulo, Fundação Getulio Vargas - EAESP/FGV, São Paulo/SP, Brasil. E-mail: joao.victor.villaverde@ gmail.com. Orcid: https://orcid.org/0000-0003-4887-3874.

* Foi visiting scholar na School of International and Public Affairs (SIPA) da Universidade de Columbia, New York - NY, EUA.

x Professor nos Programas de Graduação e Pós-Graduação acadêmica na Escola de Administração do Estado de São Paulo, Fundação Getulio Vargas - EAESP/FGV, São Paulo/SP, Brasil. E-mail: jose.rego@ fgv.br. Orcid: https://orcid.org/0000-0002-4176-2277.

xx É professor aposentado da Pontifícia Universidade Católica - PUC, São Paulo/SP, Brasil. Submetido: 25/Março/2020. Aprovado: 10/Março/2021.
} 
the invitation of his friend and minister Luiz Carlos Bresser-Pereira, the Brazilian negotiator of the external debt. Less theoretical than Bresser but as pragmatic as him, Bracher shared his friend's immense intellectual curiosity, having helped in the exchange of reflections among the different economists involved with the theory of inertial inflation. A man of action, in the private and public sectors, Bracher has a trajectory that highlights the overcome of difficulties present in national economic policy.

KEYWORDS: Brazilian economy; public administration; external debt; developing countries; State.

JEL Classification: A10; E60; H63; H81; H83.

\section{INTRODUÇÃO}

"Viver é lutar", vaticinou Gonçalves Dias três séculos atrás. A frase faz parte de poesia que o pai de Luiz Carlos Bresser-Pereira lia a ele e ao irmão Sylvio Luiz quando eram crianças, em São Paulo, no começo da década de 1940. Ela foi lembrada por Bresser-Pereira no trecho final do livro autobiográfico Rupturas do Pensamento (Editora 34, 2021). Viver, de fato, é lutar. A frase pode ser aplicada àqueles com espírito público, que fizeram de suas trajetórias privadas - seja em empresas, seja em universidades - caminhos para chegar ao setor público brasileiro, com o objetivo de transformar para melhor a vida de seus contemporâneos. Esse leitmotiv também pode ser aplicado a Fernão Carlos Botelho Bracher. Meses mais novo que Bresser (este nascido a 30 de junho de 1934, aquele a 3 de abril de 1935), Bracher faleceu no início de 2019. Revisitar, ainda que brevemente, sua trajetória intelectual e de vida pública é o que se propõe este artigo. À luz do difícil quadro por que passa o país, rememorar casos biográficos serve também ao propósito da análise histórica do avanço institucional na administração pública brasileira. Homens de ideia, homens de ação, Bresser e Bracher tentaram influenciar seus contextos históricos. ${ }^{1}$ Embora sem o mesmo vigor teórico que Bresser, Fernão Bracher compartilhou do mesmo tempo histórico e, mais importante para o artigo em tela, da mesma motivação de trabalhar no governo de seu país para promover seu desenvolvimento econômico e tentar melhorar métodos e instituições da administração pública.

O presente artigo faz uma breve genealogia dos dois ramos familiares de Fernão Bracher - os Arruda Botelho e os Bracher - para em seguida entrar no ponto mais importante, qual seja, as participações de Bracher nos governos brasileiros. Para tanto, este artigo está apoiado em pesquisa bibliográfica multifacetada, que inclui não apenas obras históricas, mas também registro oral, anotações em diários de protagonistas e memórias. Por fim, restará claro que avanços institucionais da administração pública brasileira - notadamente na renegociação da dívida externa do

\footnotetext{
${ }^{1}$ Seguimos, aqui, linha semelhante àquela que desenvolvemos em Villaverde, J. e Rego, J.M. (2021), "Prebisch, Furtado y Bresser-Pereira: aportes de los padres del desarrollismo clásico y el nuevo desarrollismo", El Trimestre Económico, vol. 88, n. 350.
} 
setor público, mas também no combate à inflação descontrolada - é resultado não apenas de profunda reflexão teórica de mentes brilhantes, mas também de ações práticas de pessoas com elevado espírito público.

\section{GENEALOGIA FAMILIAR E A AMIZADE COM BRESSER-PEREIRA}

Como ficará claro mais adiante, Fernão Bracher era um homem conservador no plano político, enquanto nacionalista no campo econômico, com ações decisivas neste sentido. Antes de nos aprofundarmos em suas ideias e suas práticas no campo econômico, cumpre diagnosticar seu conservadorismo no campo político e cultural. Pistas explicativas para isso podem vir de sua base familiar, profundamente enraizada nos usos e costumes do país durante o período imperial e monárquico. Ancestrais de Fernão Bracher fizeram parte da política brasileira no século XIX, quando instalados no interior do estado de São Paulo. Nos parágrafos a seguir narraremos muito brevemente esses antecedentes históricos de sua família.

Até o início do século XVIII, o Oeste Paulista "urbanizado" estendia-se, no máximo, até a região onde hoje está localizada a cidade de Rio Claro - depois deste território, a região era tida como "sertão", pois ainda permanecia sob o domínio dos indígenas. ${ }^{2}$ Uma das primeiras referências sobre o "sertão de Araraquara" do qual faria parte São Carlos (município onde se situa hoje a Fazenda Pinhal dos Arruda Botelho, propriedade da família de Fernão Bracher) foi realizada por um cientista português que explorava o rio Tietê no início do século XVIII. Devido ao isolamento, escravos fugitivos, degredados e aventureiros eram atraídos para a região nesse período. ${ }^{3}$

A área que originou a sesmaria do Pinhal, de acordo com Truzzi (2000), foi concedida primeiramente em 1781 a Manuel Martins dos Santos Rego, cirurgião-mor do Regimento de Voluntários Reais de São Paulo que, cinco anos mais tarde, vendeu as terras a Carlos Bartholomeu de Arruda Botelho, sargento-mor de Itu, que foi um dos defensores do forte do Iguatemi na luta contra os espanhóis e avô do Conde do Pinhal. A sesmaria do Pinhal começou a ser explorada por volta de 1830 pelo filho mais moço de Carlos Bartholomeu, o tenente-coronel Carlos José Botelho. Ele antecipou-se ao movimento de ocupação das terras do Oeste Paulista pelos fazendeiros do café ocorrida no final da segunda metade do século XVIII. ${ }^{4}$ Em 1831 ele realizou a demarcação das terras que compuseram o núcleo da sesmaria do Pinhal e iniciou a construção da Casa-Grande. O total das terras abarcava aproximadamente quarenta mil alqueires paulistas. Carlos José Botelho transformou-se em um dos mais importantes fazendeiros da região. Um dos seus filhos, Antônio Carlos Botelho,

\footnotetext{
${ }^{2}$ Côrrea (1967), p. 22.

${ }^{3}$ Ibidem, p. 23.

${ }^{4}$ Truzzi (2000), p. 84.
} 
em 1840 iniciou uma plantação de café pioneira na região, com cinco mil mudas. O café logo alcançou outras fazendas da região e suplantou os demais produtos, como a cana-de-açúcar e a criação de gado. Antônio Carlos casou-se, em 31 de maio de 1852, com Francisca Theodora Ferraz Coelho. Em 1854, após a morte de seu pai, Antônio Carlos, mesmo não sendo o filho mais velho, assumiu a liderança da família e da política regional, iniciando sua carreira como Juiz de Órfãos. ${ }^{5}$ No ano seguinte, ele derrubou a mata da área reservada por seu pai e delineou o terreno para a construção da capela da futura vila de São Carlos. Truzzi (2000) também considera que Antônio Carlos foi o fundador de São Carlos (oficialmente fundada a 4 de novembro de 1857), pois foi ele quem se esforçou e trabalhou para a construção e o desenvolvimento da cidade. Em 1862, Francisca Theodora, sua esposa, veio a falecer e, um ano mais tarde, Antônio Carlos casou-se novamente, desta vez com Ana Carolina de Mello Franco e Oliveira, filha do Coronel José Estanislau de Oliveira - que recebeu os títulos de Barão de Araraquara e de Visconde do Rio Claro. Em 1868, Antônio Carlos foi reeleito deputado geral, já filiado ao Partido Liberal. Sua fazenda recebia vários hóspedes ilustres, tais como Joaquim Nabuco e Rui Barbosa. Cumpre notar que essa relação entre grandes produtores de café e a política foi diagnosticada por Celso Furtado:

A proximidade da capital do país constituía, evidentemente, uma grande vantagem para os dirigentes da economia cafeeira. Desde cedo eles compreenderam a enorme importância que podia ter o governo como instrumento de ação econômica. Essa tendência à subordinação do instrumento político aos interesses de um grupo econômico alcançará sua plenitude com a conquista da autonomia estadual, ao proclamar-se a República [...] Mas não é o fato de terem controlado o governo o que singulariza os homens do café. E sim que tenham utilizado esse controle para alcançar objetivos perfeitamente definidos de uma política. É por essa consciência clara de seus próprios interesses que eles se diferenciam de outros grupos dominantes anteriores ou contemporâneos. ${ }^{6}$

O cultivo do café estava se firmando como a grande riqueza do Segundo Império, liderando já a partir de 1850 a pauta exportadora brasileira e apenas cinco décadas mais tarde tornando-se basicamente o "centro motor" da economia do país. ${ }^{7}$ As exportações do Brasil, que haviam atingido a média de 3,6 milhões de sacas por ano em 1868-71, atingiram 3,3 milhões em 1873-76, mas essa queda de volume foi mais do que compensada pelo aumento de preço internacional do produto que dobrou. ${ }^{8}$ Com isso, trilhos para ferrovias se impunham, de forma a acelerar o

\footnotetext{
${ }^{5}$ Truzzi (2000), p. 85.

${ }^{6}$ Furtado (2009), p. 183.

${ }^{7}$ Ribeiro (2020), p. 5.

${ }^{8}$ Delfim Netto (2009), p. 23.
} 
transporte da produção dos cafezais para os portos e também para o mercado que começava a se formar no litoral urbanizado. ${ }^{9}$ Em 1872, Campinas passou a contar com os trilhos da Companhia Paulista, e, quatro anos mais tarde, Antônio Carlos apresentou a proposta de se estender a estrada de ferro até a cidade de São Carlos. Para tanto, ele fundou a Companhia de Estrada de Ferro de Rio Claro juntamente com o engenheiro, então recém-formado, Antônio Francisco de Paula e Souza, que mais tarde exerceu o cargo de primeiro diretor da Escola Politécnica em São Paulo. ${ }^{10} \mathrm{~A}$ expansão das ferrovias, às vezes, dava-se sem a subvenção governamental, como no caso da Companhia Rio Claro. Truzzi (2000), ao comentar a definição do traçado da estrada de ferro, faz o seguinte registro: "Além de influenciar o Governo Imperial, no sentido deste fazer vir os trilhos da ferrovia até São Carlos, o Conde do Pinhal, como representante de um vasto conjunto de oligarquias locais, determinou o traçado que melhor conviria aos interesses de seus amigos e parentes fazendeiros" ${ }^{11}$ O período de expansão das ferrovias também foi um período de grande transformação sociocultural das cidades da província. ${ }^{12}$

Assim, pelo lado materno, a família Arruda Botelho entrou no século XX com laços diretos com o principal produto de exportação (o café), com a política local e nacional (pelo Partido Liberal) e com as grandes propriedades de terra. Em uma frase, podemos dizer que os Arruda Botelho eram parte constitutiva do establishment daquele período. Eram parte de um todo que atuava, em linhas gerais, no campo conservador. Como nota Bresser (2016):

Essa elite [no Império] era conservadora, e acabou por ser a força atuante na construção do Estado brasileiro, porque sabia que ele representava a lei e a ordem, mas ela se dedicou a essa tarefa com dificuldade, porque sua experiência colonial havia sido eminentemente privatista ao invés de pública [...] a construção do Estado no Império não estava voltada para a construção de uma nação. Não havia nas elites brasileiras nenhuma atitude "anti" em relação ao imperialismo que geralmente acompanha a formação de uma nação cujo desenvolvimento é retardatário; essas elites não se davam conta de que o imperialismo industrial ou moderno limitava o desenvolvimento do país, entre outras razões, porque o persuadia a não buscar a industrialização. ${ }^{13}$

Uma das netas do cafeeiro e político Antônio Carlos, Zila Arruda Botelho, conheceria em São Paulo o jovem contador Eduardo Bracher, com quem se casaria.

Pelo lado paterno, Fernão Bracher descendia de avó alsaciana que nascera em

\footnotetext{
${ }^{9}$ Ibidem, p. 6.

${ }^{10}$ Truzzi (2000), p. 82.

${ }^{11}$ Ibidem, p. 83.

12 Martins (1990).

${ }^{13}$ Bresser (2016), p. 67-68.
} 
Mulhouse e deixou seu país quando a região foi anexada pelo Império Alemão. ${ }^{14}$ Seu avô paterno, Godofredo, foi o primeiro filho nascido no Brasil, oriundo de uma família de emigrantes do cantão de Berna, na Suíça. Godofredo nasceu em Curitiba e cedo trabalhou em seguradora. ${ }^{15} \mathrm{O}$ pai de Fernão, Eduardo, já nasceu em São Paulo, onde estudou contabilidade no Mackenzie. "O meu pai tinha uma situação de classe média e pôde se casar com uma moça da antiga aristocracia cafeeira", contaria Bracher. ${ }^{16}$ Seu pai, Eduardo, se separou relativamente cedo de Zila Arruda Botelho, tendo Fernão basicamente tido a criação com o pai e em parte com os avós Bracher em São Paulo, pois sua mãe se muda para o Rio de Janeiro, então a capital da República. É na casa de seus avós paternos que aprende o idioma alemão, algo que seria instrumental para sua trajetória.

Em 1957, terminado seu curso na Faculdade de Direito da Universidade de São Paulo, Fernão se casa com Sonia Sawaya e vão morar na Alemanha Ocidental, onde viveu por dois anos como tradutor em Heildelberg, e depois já trabalhando em um escritório de advocacia em Munique. Sua formação em Direito seria fundamental para a trajetória intelectual e pública de Fernão Bracher. Em sua turma estava o amigo de adolescência e companheiro na Juventude Universitária Católica, Luiz Carlos Bresser-Pereira. A ele, damos a palavra:

Nesta época nosso grupo tinha boas relações com os padres dominicanos, que eram politicamente progressistas. Fernão e eu fomos estudar Filosofia com eles [...] O meu melhor amigo foi o Fernão Bracher [...] ambos tínhamos em comum o nacionalismo econômico e o espírito público. Fernão sempre foi um conservador, eu, um progressista. Mas nos respeitávamos apesar de nem sempre estarmos de acordo um com o outro. Eu o admirava e ele me admirava apesar de algumas vezes achar que eu ia muito longe nas minhas ideias progressistas. Vera Cecília e eu fomos padrinhos do Candido, o primeiro filho dele e de Sonia. Candi nasceu na Alemanha, quando eles moraram lá após Fernão terminar a Faculdade de Direito. Fernão e Sonia foram os padrinhos de nossa primeira filha, Patrícia, que nasceu pouco depois. ${ }^{17}$

Quando do seu retorno ao Brasil, no início de 1960, Fernão Bracher teve sua última experiência na área original de graduação, como advogado do escritório Pinheiro Neto. No ano seguinte entrou para o setor bancário, como assistente de diretor do Banco da Bahia. Por 12 anos trabalhou no banco, chegando a diretor da área externa. Em 1973 o banco foi adquirido pelo Bradesco e Amador Aguiar,

\footnotetext{
${ }^{14}$ Klüger (2017), p. 515.

15 Ibidem.

${ }^{16}$ Ibidem.

${ }^{17}$ Villaverde e Rego (2021), p. 41-42.
} 
maior acionista deste último, convidou Bracher a permanecer no cargo. Por um ano, Bracher trabalhou como diretor do Bradesco, aproximando-se do "dono":

O Amador Aguiar era um artista, pegava a coisa pelo cheiro e representava. Gostava de encenações, fazia o tipo, aquelas festas do Bradesco com a banda de música... ele realmente tinha o dom da encenação pessoal, planejada da direção dos homens... junto com tudo era um exímio bancário, dotado de grande capacidade de trabalho, perspicácia negocial e ambição, era extraordinário. ${ }^{18}$

Bracher, então, teve a primeira oportunidade de entrar para a vida pública brasileira. Aceitou. Com isso, entramos no que consideramos um dos eixos centrais do presente artigo: a ação na administração pública de brasileiros preocupados com o interesse nacional.

\section{A PREOCUPAÇÃO COM O INTERESSE NACIONAL E A AÇÃO PÚBLICA}

Ernesto Geisel assumiu a Presidência da República em março de 1974 com o objetivo declarado de promover a distensão política do regime militar, instalado após o golpe dez anos antes. Iniciava a fase da "abertura lenta, segura e gradual". O novo presidente convidou Mário Henrique Simonsen para Ministro da Fazenda e Paulo Pereira Lira como Presidente do Banco Central. Em seguida, Fernão Bracher é convidado a se tornar diretor da área cambial do Banco Central (BC). Semanas antes estourara o primeiro choque do petróleo, que fez o preço do barril do produto disparar no mercado internacional, provocando um surto de inflação global. Naquele período, também, começava a vigorar o regime de câmbio livre nos Estados Unidos, depois que o presidente Richard Nixon anunciou o rompimento formal com o "padrão-ouro", em 1971. No Brasil, com a combinação de escassez de divisas internacionais, aumento do preço do petróleo e o regime de minidesvalorizações periódicas da moeda nacional (o cruzeiro), a missão de Bracher era organizar o fluxo de capitais ao país, com planos de liberalizar regras e permitir ajustes mais rápidos da taxa de câmbio. ${ }^{19}$ Por cinco anos Bracher prestou serviços públicos como diretor do BC em Brasília, desempenhando funções exclusivamente técnicas, sem relação alguma com a política. ${ }^{20}$ Deixou o cargo em março de 1979 , quando Geisel passou a faixa presidencial a João Figueiredo.

De volta ao setor privado (inicialmente na seguradora Atlântica Boavista e depois novamente no Bradesco, onde assumiu como um dos vice-presidentes executivos do banco), Fernão Bracher estava especialmente curioso com o processo inflacionário

\footnotetext{
${ }^{18}$ Rego et al. (2004), p. 500.

${ }^{19}$ Banco Central (2019), p. 9.

${ }^{20}$ Ibidem, p. 20.
} 
brasileiro. A inflação, persistentemente alta, já estava claramente fora do controle do governo quando a década de 1980 começou. Os principais economistas brasileiros passaram, então, a deslocar todo o seu esforço de reflexão para a compreensão do problema inflacionário, seguido de propostas de soluções. Muito amigo de Bresser-Pereira - sócio-diretor do Grupo Pão de Açúcar, doutor em economia pela USP e professor na EAESP (FGV) - que então construía com Yoshiaki Nakano a teoria da inflação inercial, Bracher se inteirou das novas ideias e passou a fazer o papel de "ponte" entre as reflexões de seu amigo e dos economistas da PUC-Rio, notadamente André Lara Resende, Persio Arida, Edmar Bacha e Francisco Lopes, que estavam trabalhando nessa mesma teoria. Os dois mundos passaram a ter, em 1981, uma ponte formal de comunicação, com a fundação, por Bresser, da Revista de Economia Política (hoje Brazilian Journal of Political Economy). Bracher, portanto, "antecipara" essa ponte em alguns meses, além de torná-la também informal e fraterna ao longo dos anos seguintes. ${ }^{21}$

Eram duas, basicamente, as missões primordiais dos homens e mulheres com espírito público no Brasil naqueles anos: redemocratizar o país (superando a ditadura militar) e debelar a inflação alta (beirando a hiperinflação). Tal como seu mestre Celso Furtado, Bresser-Pereira ingressa no PMDB. Em 1982, o senador paulista Franco Montoro obtém uma importante e simbólica vitória eleitoral. Assume como governador em março de 1983 e convida Bresser para ser o presidente do Banespa e, depois, a secretário de Governo. Enquanto trabalhava no governo democrático de Montoro, Bresser mantinha suas reflexões sobre a inflação inercial (que levaria à publicação do livro Inflação e Recessão, com Yoshiaki Nakano, em 1984). Sempre curioso com as ideias do amigo, Bracher acompanha a luta pela redemocratização do Brasil e, em particular, os debates entre os economistas da PUC-Rio e da FGV-SP sobre a inflação inercial e os possíveis caminhos para solucionar essa chaga social. Essa curiosidade de Bracher foi de crucial importância dado que, muitos anos depois, ele reconheceu não ter, inicialmente, compreendido o caráter inercial da inflação brasileira naquele momento. "Foi meu maior erro", admitiu. ${ }^{22}$ As interações frequentes com Bresser e com o grupo de economistas da PUC-Rio, isto é, com o seleto coletivo que realmente compreendia o problema da inflação brasileira, foi de suma relevância para Bracher.

A chapa de oposição civil ao regime militar, com Tancredo Neves para presidente e José Sarney para vice, é eleita no colégio eleitoral em janeiro de 1985. Tancredo adoece e é internado na véspera. Sarney cumpre o prometido e assume o governo com todos os ministros selecionados por Tancredo. Coloca de pé uma emenda constitucional para permitir o voto dos analfabetos e tenta, aos poucos, tomar pé da dramática situação institucional legada pelos militares aos civis. Em agosto de 1985, Sarney realiza a primeira mudança ministerial de peso, substituindo Francisco Dornelles por Dilson Funaro no Ministério da Fazenda. Este chega em Brasília imbuído

\footnotetext{
${ }^{21}$ Villaverde e Rego, (2021), p. 147.

22 Banco Central (2019), p. 22.
} 
de debelar a inflação. Leva com ele economistas da PUC-Rio e, para a presidência do Banco Central, convida Fernão Bracher. "A fogueira que devorou o ministro da Fazenda [Dornelles], não isenta de algumas fagulhas de perfídia, liquidou a herança. O governo está, definitivamente, entregue a si mesmo, forçado a conquistar a confiança popular e a executar um programa autônomo", anotaria naqueles dias o jurista e escritor Raymundo Faoro. ${ }^{23}$ Ele concluiria com uma pergunta: “Terá a equipe do novo ministro da Fazenda, qualificada pela alta competência acadêmica, tempo para ganhar o tempo perdido?". ${ }^{24}$

\section{TEMPOS TURBULENTOS}

Bracher aceitou deixar a vice-presidência do Bradesco em São Paulo para mudar-se para Brasília e ser o presidente do Banco Central nas primeiras semanas de governo civil após 21 anos de regime militar. Estava para começar um período especialmente rico em experiências. Entre agosto de 1985 e fevereiro de 1987, quando pediu demissão, ele liderava a autoridade monetária justamente quando o governo implementou a primeira troca de moeda da economia brasileira em 44 anos, ao substituir o cruzeiro pelo cruzado. Além disso, Bracher participou ativamente das diversas mudanças institucionais daquele período, como o fim da conta-movimento que havia entre o governo federal e o Banco do Brasil (BB), encerrando um longo período histórico em que o $\mathrm{BB}$ exercia papéis que deveriam ser de exclusividade do BC. Bracher leva a trabalhar com ele no Banco Central dois economistas com quem mantinha contato desde o início da década, por conta dos debates sobre a inflação: Persio Arida e André Lara Resende. Eram tempos de redemocratização, tempos difíceis, tempos de descobertas. Depois de duas décadas consecutivas de uma máquina pública pouco transparente e insulada das pressões sociais, os primeiros servidores em governos estaduais (como Bresser-Pereira no governo Montoro a partir de 1983) e no governo federal (como Fernão Bracher e equipe no governo Sarney a partir de 1985) descobriam a todo momento que estavam cercados de "esqueletos". Já em meados de 1985 estava claro para Sarney e para o PMDB que as mudanças para redemocratizar o país não poderiam ficar circunscritas à abertura política e eleitoral, mas também deveriam envolver modernizações da política econômica. ${ }^{25}$ Novas ideias, novas pessoas no comando eram necessárias. Segundo Bracher:

Eu conhecia o presidente Sarney desde a época em que fui diretor do Banco Central. Mais de uma vez, convidei-o para jantar, conversar. Então, ele tinha uma ideia de quem eu era. As outras fontes que consultou tam-

\footnotetext{
${ }^{23}$ Trechos de artigo "A hora da verdade", de Faoro, publicados originalmente a 11/09/1985 na revista Isto É/O Senhor. Retiramos de Faoro (2018), p. 153.

${ }^{24}$ Faoro (2018), p. 154.

${ }^{25}$ Bastos (2001), p. 30.
} 
bém se mostraram favoráveis à minha indicação, e o convite foi feito. Essa passagem pelo Banco Central, no entanto, foi muito menos calma e tranquila do que a dos tempos de Geisel. De fato, a situação econômica era muito pior, a inflação ameaçando sair do controle, o sistema bancário fragilizado, e o Brasil em conflito aberto com a comunidade bancária internacional. Era necessário reconstruir nossa segurança de que o sistema bancário estava saudável. Havia três áreas que precisavam de atenção. A primeira delas, mais do que uma escolha, foi uma imposição: era necessário sanear o Sistema Financeiro Nacional (SFN). Precisávamos trabalhar para solucionar problemas de três bancos [...] [que] estavam em situação muito difícil, já com o patrimônio negativo [...] outra área particularmente complexa era a área externa. Passávamos por problemas com os bancos internacionais. Reuníamo-nos frequentemente com representantes dos bancos estrangeiros, coordenado, em geral, pelo Citibank. [...] superado esse desafio, estávamos preparados para enfrentar o terceiro: a inflação. E as ideias que tínhamos para enfrentá-la, na época, eram as de Persio [Arida] e de André [Pinheiro de Lara Resende], meus diretores no Banco Central [...] quem também já havia escrito sobre isso foi o [Luiz Carlos] Bresser [Pereira] e o [Yoshiaki] Nakano. No entanto, independentemente do resultado, Persio, André e Bacha trabalharam muito bem. Assim como o Chico Lopes. ${ }^{26}$

Um momento muito turbulento começara. De início, o Plano Cruzado (anunciado de surpresa pelo governo Sarney na manhã do dia 28 de fevereiro de 1986) deu muito certo. A inflação despencou. A combinação entre moeda nova, preços congelados por decreto do governo e aumento de salários gerou um entusiasmo nacional, transformado em consumo acelerado. A economia reagiu rapidamente (o PIB de 1986 terminaria por crescer 7,8\%, de acordo com dados do IBGE). No fim do ano, no entanto, a escassez de produtos gerou uma correção de rota brusca - e atrasada. O Plano Cruzado II, anunciado apenas três dias após as eleições gerais, gerou a grande insatisfação popular e instabilidade urbana. O quadro da dívida externa tornara-se especialmente complicado quando a inflação retornou com velocidade, e nas primeiras semanas de 1987 ficou claro que o presidente da República se tornara simpático às ideias de uma corrente de economistas mais à esquerda, que defendiam a moratória dos pagamentos aos credores. Bracher decidiu deixar o governo naquela ocasião, em fevereiro de 1987. Sarney anunciou a moratória (e mais tarde reconheceria ter sido um grande equívoco) ${ }^{27}$ Abalado, Funaro deixa o cargo em abril e é substituído por Bresser-Pereira no comando do Ministério da Fazenda.

\footnotetext{
${ }^{26}$ Banco Central (2019), p. 41 e 43.

${ }^{27}$ Bastos (2001), p. 47.
} 


\section{A DÍVIDA EXTERNA E OS AVANÇOS INSTITUCIONAIS NA ADMINISTRAÇÃO PÚBLICA BRASILEIRA}

O quadro geral do país quando Luiz Carlos Bresser-Pereira assume o Ministério da Fazenda era desalentador. O fracasso do Cruzado aumentara exponencialmente a taxa de inflação, enquanto o crescimento econômico perdia fôlego. A Constituinte, a pleno vapor, gerava incentivos populistas à esquerda, à direita e ao centro. A moratória, declarada em fevereiro, gerou enorme aversão internacional a ativos brasileiros. Homens e mulheres com espírito público, no entanto, tem o desprendimento para se lançar em uma aventura inglória. Bresser aceitou o enorme desafio e formou sua equipe de confiança. Convidado por Bresser-Pereira a assumir a delicada reabertura de negociações com os credores da dívida externa brasileira, Bracher aceita voltar ao governo federal apenas semanas depois de pedir demissão do Banco Central.

Era uma missão difícil para os dois. Bresser buscaria o ajuste fiscal enquanto o governo e também o Congresso Nacional (em plena Constituinte) tinham incentivos para aumentar gastos, em vez de reduzir despesas. Bresser também tentaria o controle da inflação, que estava ainda mais descontrolada do que antes do Cruzado. Por fim, Bresser buscaria pontes com países emergentes (notadamente México e Argentina) de forma a consolidar posições na difícil negociação com os países ricos envolvendo a dívida externa. Para esta última missão, Bresser confiou a Fernão Bracher um papel decisivo.

Ainda em maio, o Fundo Monetário Internacional (FMI) enviou ao Brasil uma missão de consulta e Bracher retomou entendimentos com os bancos, ${ }^{28}$ acenos importantes da nova gestão, liderada por Bresser, para reduzir as animosidades inflamadas após a declaração da moratória. Por seis meses, Bracher viajou o mundo, negociou com diversas partes, refletiu e conversou muito. Ao final, Bresser e Bracher chegaram a uma proposta de renegociação que resolveria os problemas de todos os países atingido pela crise da dívida externa. Como conta Bresser-Pereira:

Comecei, então, a montar a proposta. Precisava, primeiro, convencer o Fernão Bracher, que era meu negociador da dívida externa e um homem cauteloso. Ele achou a ideia ousada, ficou com receio de que acabaria não dando certo, mas ouviu meus argumentos e concordou. Na minha equipe, afinal, todos concordaram com a ideia. Precisei, naturalmente, convencer o Sarney, mas não foi difícil. Ele é um nacionalista, não entendeu completamente a proposta, mas o suficiente para dar seu apoio. ${ }^{29}$

A proposta foi concluída no dia 24 de setembro de 1987 e apresentada publicamente aos credores no dia seguinte. Segundo precioso texto "escrito a quente" por Bracher e publicado na Brazilian Journal of Political Economy no fim do ano seguinte

\footnotetext{
${ }^{28}$ Nóbrega (2010), p. 365.

${ }^{29}$ Villaverde e Rego (2021), p. 169.
} 
(1988), a proposta brasileira era "construtiva, simples, inovadora e moderada" e assim "foi entendida pelos círculos governamentais" de cada parte.

Impunha-se começar a procurar uma solução definitiva, a qual só se obteria na medida em que se reestruturasse a dívida de acordo com a efetiva capacidade de pagamento do país [...] Para assegurar a regularidade do serviço da dívida com o crescimento econômico e estabilidade de preços, entendeu-se necessário ter uma reestruturação a longo prazo que usasse novos instrumentos, como os bônus; novos incentivos, como a sua conversão em investimento e reempréstimo, e atentasse às indicações de mercado relativamente ao valor do crédito brasileiro. ${ }^{30}$ (grifos nossos)

Tratava-se, portanto, de uma proposta de securitização da dívida externa brasileira, envolvendo instrumentos de mercado para repactuar o principal devido, as taxas de juros e o formato da amortização.

No entanto, Bracher aponta que os bancos credores do Brasil não apresentaram a mesma receptividade. Como conta Bresser, a proposta brasileira foi recebida como um "non-starter" pelo Secretário do Tesouro, James Baker. Mas interessou muito aos bancos credores, que logo compreenderam que ali havia uma "solução de mercado" para seus créditos congelados em contratos. Assim, 18 meses mais tarde, o novo Secretário do Tesouro, Nicholas Brady, adotou o Plano Brady que era, ponto por ponto, igual à proposta de Bresser e Bracher.

As anotações de Celso Furtado em seus diários, contemporâneo ativo desses acontecimentos (Furtado era, afinal, amigo de Bresser e seu colega de ministério), são reveladoras. A 10 de maio de 1987, Celso Furtado escreveu que jantara com o presidente José Sarney e com Severo Gomes no sítio presidencial, em Brasília, e que Sarney "contou-nos reservadamente que Bresser quis trazer o Bracher de novo para o Banco Central". ${ }^{31}$ No fim do ano, a 30 de outubro, Furtado anotou em seu diário que tomara café da manhã com Bresser naquele dia, registrando em seguida que "o negociador de Bresser [para a dívida externa] é Fernão Bracher, seu amigo, é verdade, mas que foi escolhido para tranquilizar a comunidade financeira, cujo peso o Bresser conhece". ${ }^{32}$

Até 18 de dezembro, quando Bresser pede demissão do governo, Fernão Bracher comanda as negociações com credores. Ele deixa o cargo juntamente com o amigo; durante os dias finais do ano escreve um texto franco, que entrega a 5 de janeiro de 1988 a Maílson da Nóbrega, sucessor de Bresser. A despeito das enormes dificuldades, Bracher anotava otimismo com o futuro da proposta: "O tempo caminha a nosso favor. Há um reconhecimento generalizado de que a sistemática até agora

\footnotetext{
${ }^{30}$ Bracher (1988), p. 116.

${ }^{31}$ Furtado (2019), p. 344.

32 Ibidem, p. 353.
} 
perseguida está errada e algo de fundamentalmente diferente deve ser feito". ${ }^{33}$ Como anos depois contaria Bracher:

Foi necessário plantar a ideia [da securitização da dívida externa], sofrer a recusa [dos credores] e deixar, em um segundo momento, que a ideia voltasse quase como sendo dos credores. E, de fato, foi a securitização que resolveu o impasse e, mais tarde, inclusive possibilitou uma marginal redução da dívida, através da combinação do prazo e taxa de juros. Esse mérito do Bresser é pouco reconhecido. Ele plantou e os outros, todos nós, colhemos. ${ }^{34}$

Bresser retomaria a vida pública mais duas vezes, tornando-se ministro da Reforma do Estado entre 1995 e 1998 e ministro da Ciência e Tecnologia, em 1999. Lideraria a emenda constitucional de modernização da administração pública federal, entre outras mudanças legais e infralegais. Fora do governo, aprofundaria suas reflexões sobre política econômica (com a teoria do novo desenvolvimentismo) e sobre sociedade e sistemas econômicos.

Fernão Bracher, por sua vez, não retornaria ao setor público depois de entregar a Maílson da Nóbrega o seu relato sobre a tentativa de renegociar a dívida externa brasileira. Em 1988, aos 53 anos, Bracher estava de volta a São Paulo e, desta vez, seu objetivo era tornar-se banqueiro.

\section{DE BANCÁRIO A BANQUEIRO}

Quase três décadas depois de trabalhar como bancário (e em seguida diretor) do Banco da Bahia, Fernão Bracher decidiu mudar para o outro lado da mesa. Já tinha chegado à vice-presidência de um grande banco privado, o Bradesco. Já tinha sido até banqueiro, mas no setor público, como presidente do Banco Central. Eduardo, o pai de Fernão, falecera naquele momento e, segundo o próprio testemunho do filho, ele estava determinado a usar os recursos patrimoniais que tinha à disposição naquela oportunidade, em 1988, para ter seu próprio banco. ${ }^{35}$ Quando o Creditanstalt Bankverein, o mais antigo banco da Áustria, procurou Bracher para dividir o interesse de revalorizar papéis brasileiros que o banco possuíra, ele "trucou": a solução era o banco investir de fato no Brasil e, neste caso, Bracher se apresentou para ser coproprietário. "Eles concordaram com a proposta e constituímos a sociedade. Convidei para ser meu sócio Beltran, que havia sido vice-presidente do Bradesco por longo tempo e conhecia todo mundo [...] Escolhido o nome Bracher, Beltran e Associados (BBA), começamos a operar". ${ }^{36}$

\footnotetext{
${ }^{33}$ Bracher (1988), p. 116.

${ }^{34}$ Rego et al. (2004), p. 505.

${ }^{35}$ Banco Central (2019), p. 47.

36 bidem.
} 
De 1988 a 2002, Bracher comandou, com Antônio Beltran, o BBA, com apoio direto do filho do primeiro, Candido Bracher. ${ }^{37} \mathrm{O}$ novo banco foi uma extraordinária história de sucesso empresarial. Por fim, o BBA foi vendido ao Itaú, que a partir de 2003 constituiu o Itaú BBA. ${ }^{38}$ Neste período histórico, que começou com a Constituição (1988) e chegou à eleição para a Presidência da República de Luiz Inácio Lula da Silva (2003), Bracher liderou o banco. Mesmo após a fusão, Bracher e Beltran continuaram com o comando efetivo do BBA.

Em janeiro de 2019, Bracher sofreu uma queda enquanto passava férias em sua Fazenda do Pinhal (aquela formada por seu ancestral Antônio Carlos de Arruda Botelho). Ele não conseguiu se recuperar do trauma e faleceu no mês seguinte, aos 83 anos.

\section{CONCLUSÃO}

Viver é lutar. Para homens e mulheres com espírito público, a verdadeira luta se coloca quando deixam seus afazeres mais cômodos - como confortáveis posições no setor privado - para trabalhar no setor público. Lidar com a escassez de recursos, com estruturas burocráticas mais engessadas que no setor privado, com as pressões políticas (intragoverno e da oposição), negociar com agentes externos. Como vimos em artigo anterior, essas diversas facetas de pressão no setor público (ainda mais dramáticas em países subdesenvolvidos) eram verdadeiras tanto na Argentina dos anos 1930, quando Raúl Prebisch foi presidente do Banco Central, quanto no Brasil dos anos 1960 (quando Celso Furtado liderou a Sudene e depois foi ministro do Planejamento) e duas décadas mais tarde, quando Bresser-Pereira fez parte do primeiro governo democrático em São Paulo. A mesma avaliação é clara no presente artigo. Quando Bracher comandou o Banco Central no imediato pós-ditadura, entre 1985 e 1987, e em seguida liderou, sob a chefia do amigo Bresser-Pereira, as difíceis negociações sobre a dívida externa, os problemas eram incontáveis. Para a sorte do país, as experiências e a luta para modernizar, democratizar e institucionalizar a administração pública brasileira foram perenes.

Vindo de família de posses desde o século XIX, conservador na política, Bracher abriu mão em três oportunidades de usufruir de uma vida mais cômoda para trabalhar no setor público (nos anos 1970 e 1980). Em suas palavras:

O setor público tem uma grande vantagem: você sente que está trabalhando pelo seu país. Não está trabalhando para ficar mais rico. Lembro-me de que, certa vez, as passagens dos meus filhos de São Paulo para

\footnotetext{
${ }^{37}$ Candido trabalhou no BBA desde os primeiros dias: "Éramos 20 pessoas, tínhamos um patrimônio de US\$ 20 milhões e me lembro de desenharmos como seriam os boletos", in "Laços de gratidão", CEO Brasil, ano 14, no 37, 2019, p. 4-9. (https://www.pwc.com.br/pt/estudos/preocupacoes-ceos/revistaceo/2019/pwc-ceo-brasil-37.pdf - acessado em 22/7/2021).

38 "Itaú leva BBA-Creditanstalt por R\$ 3,3 bi e cria holding", jornal Folha de S.Paulo, 6/11/2002 (https://www1.folha.uol.com.br/fsp/dinheiro/fi0611200207.htm, acessado em 21/7/2021).
} 
Brasília saíram tão caras quanto meu salário mensal. Por outro lado, é um prazer enorme. Todas as suas lutas, tudo o que está fazendo não é nada para você. Desabridamente, segue-se em frente. O setor público dá um prazer muito grande. Já no setor privado, constrói-se mais livremente, tem-se mais liberdade para fazer e acontecer. Em todas as atividades que desenvolvi, sempre tive razoável liberdade..$^{39}$

\section{REFERÊNCIAS BIBLIOGRÁFICAS}

Banco Central do Brasil (2019), Coleção História Contada do BCB, Volume XII, https://www.bcb.gov. br/historiacontada/publicacoes/hc_bc_volume_12_fernao_bracher.pdf.

Bastos, O. (2001), Sarney: o outro lado da história, Editora Nova Fronteira.

Bracher, F. (1988), "Negociação da dívida externa”, Brazilian Journal of Economic Policy, vol. 8, n. 4, outubro-dezembro.

Bresser-Pereira, L.C. e Y. Nakano (1984) Inflação e Recessão, São Paulo: Editora Brasiliense.

Bresser-Pereira, L.C. (2016), A construção política do Brasil: Sociedade, economia e Estado desde a Independência, Editora 34.

Côrrea, Anna Maria Martinez (1967), História social de Araraquara: 1817-1930, Dissertação de Mestrado, USP.

Delfim Netto, A. (2009), O problema do café no Brasil, Editora UNESP.

Faoro, R. (2018), A República em Transição, Editora Record.

Furtado, C. (2019), Diários Intermitentes: 1937-2002, Companhia das Letras.

Furtado, C. (2009), Formação Econômica do Brasil, Companhia das Letras.

Klüger, E. (2017), Meritocracia de laços: gênese e reconfigurações do espaço dos economistas no Brasil. Tese de Doutorado, Faculdade de Filosofia, Letras e Ciências Humanas, Universidade de São Paulo (USP). Doi: 10.11606/T.8.2017.tde-06022017-113838.

Martins, Ana Luiza (1990), Império do café: a grande lavoura no Brasil, 1850 a 1890, Editora Atual.

Nóbrega, M. (2010), Além do feijão com arroz, Civilização Brasileira.

Rego, J.M. et al. (2004), Em Busca do Novo, FGV Editora.

Rego, J.M. et al. (1996), Conversas com Economistas Brasileiros, Editora 34.

Ribeiro, E. B. (2020), "Entre braços e brasões: um olhar sobre o desenvolvimento ferroviário no interior paulista”, Pós: Revista Do Programa De Pós-Graduação em Arquitetura e Urbanismo Da FAUUSP, 27(51).

Truzzi, O. M. S. (2000), Café e Indústria: São Carlos, 1850-1950, Editora UFSCar.

Villaverde, J. e Rego, J.M. (2021), Bresser-Pereira: Rupturas do Pensamento, Editora 34.

Villaverde, J. e Rego, J.M. (2021), "Prebisch, Furtado y Bresser-Pereira: aportes de los padres del desarrollismo clásico y el nuevo desarrollismo", El Trimestre Económico, vol. 88, n 350.

${ }^{39}$ Banco Central (2019), p .49. 